Under Dr. Flint's care she remained much the same till April 5, 1924, when owing to continued excretion of sugar she was readmitted. On April 8 and 9, 10 units insulin were given, reduced to 5 on April 10, and she has continued with this small amount till a week ago, when I saw her again.

She came for a mild conjunctivitis, R. and L.V. $=6 / 6$ unaided. She told me her eyes had rapidly improved after I had ordered the $+5 \mathrm{D}$ sph.; and that on January 2,1924 , she was able to dispense with these and had not used them since!

She now reads Jaeger No. 2 easily: the media are clear and fundi normal; shadows $+0.25 \mathrm{D}$ vertical; $+0.5 \mathrm{D}$ horizontal.

Dr. Flint reports that 5 units kept her sugar free for a year and that he is now administering raw pancreas.

This case then, a very mild diabetic (renal ?), contrary to rule developed a high-grade hypermetropia, $+5 \mathrm{D}$ sph.; and lost it under simple dietetic treatment.

I find it difficult to fit this case into any of the theories propounded, and one wonders whether at an unstable age there may not have been a sudden flooding of the system with the products of an endocrine gland which may have indirectly altered the refractive index of the lens.

Yours faithfully,
Nottingham,
A. Christie Reid.

April 25, 1925.

\title{
VISUAL REQUIREMENTS OF MOTOR DRIVERS
}

To the Editor of The British Journal of Ophthalmology

SIR,-In the April number of your journal you refer at some length to a report read before the Ophthalmological Section of the American Medical Association in June of 1924. It might be well to accentuate that this report has not yet been accepted by either the Section on Ophthalmology or by the American Medical Association, indeed, it was referred back to the committee for certain modifications in the visual standards.

The report, with these modifications, will be presented at the coming meeting of the Association in May and, if accepted by the Section on Ophthalmology, will, in conjunction with standards prepared by the Section on Preventive and Industrial Medicine and Public Health, which cover examinations of other parts of the body, be submitted to the House of Delegates for action. If this be favourable, the entire matter will be referred to a department of the Association which has charge of public health and policies with a view to introducing the standards into the various States of our country. 
It is natural, I suppose, that our committee should think better of the standards they have suggested than their British colleagues apparently do. To us the requirements seem moderate and practical. All examinations are put in the hands of qualified practitioners, with provisions for a re-examination by a Board of three practitioners in all vexed or doubtful cases.

The expedient suggested by the British Medical Journal to require no standards of physical fitness other than, the signed declaration of each candidate: "that to the best of his belief he has no defect or disease which makes him unfitted to drive a car or motor-cycle," seems to us to place too great a strain upon the judgment and conscience of the average individual.

Our committee is hopeful that the standards they have proposed may be better received in America than the British Medical Journal and the British Journal of Ophthalmology believe they warrant, and have a more general adoption than the suggestions embodied in the excellent report of the Council of British Ophthalmologists published in 1920 .

$$
\begin{aligned}
& \text { Yours very truly, } \\
& \text { W'M. CAMPBELL PoSEY } \\
& \text { for The Committee. }
\end{aligned}
$$

Philadelphia,

April 24, 1925.

\section{NOTES}

WE do not as a rule comment on the death

Deaths of even outstanding members of the medical profession, unless they were, in life, in some way connected with ophthalmology; but exception must be taken in the case of Sir Rickman Godlee, Bart., K.C.V.O., whose recent death will be fresh in the minds of our readers. A past master in the writing of biographies, he wrote for us the splendid monograph on Wharton Jones, published in an earlier volume; and the kindly appreciation, in itself a very difficult task, of Sir Jonathan Hutchinson which appears in this number; while his life of his uncle, Lord Lister; is a model of what a biography should be. It is most unfortunate for us that he died before he could begin a biography of Sir William Bowman, which he had undertaken to write. No one else could have done it so well.

We regret to record the death of Julius Hirschberg on February 17, in his 82nd year. Born in Potsdam in 1843, he had a distinguished career at school, began his ophthalmic work in von Graefe's clinic in Berlin, and also studied in Vienna, Prague, 